\title{
Reply to letter to Editor
}

Dear Editor,

On behalf of all the authors, I wish to thank the reader for his thorough study and incisive analysis of the article. We are grateful to him for enlightening us on several points which we did not think of and some points we could not cover in detail, the topic being vast.

1. The US classification by the WHO Informal Working Group on Echinococcosis does not give the names of the panelists involved and hence the details remain incomplete in the reference.

2. We agree that the list of scolicidal agents is incomplete. The very fact that there exist several studies on such agents as cited by the reader proves that there is no consensus on any particular agent. We chose not to discuss this in the surgery section since we have noticed that surgeons operating on hydatid cysts will continue to use one particular scolicidal agent with which he is comfortable in all his series of cases.

We once again thank the reader for highlighting several facts in the addendum.

Contributed by

Brig S. Rajagopalan

Brig Med, HQ ATNK \& K, India

0377-1237/\$ - see front matter (c) 2012, Armed Forces Medical Services (AFMS). All rights reserved. http://dx.doi.org/10.1016/j.mjafi.2012.12.003 